\title{
Perancangan dan Pembuatan Penetrometer untuk menentukan Konsistensi Tumor Otak
}

\author{
Yanurita Dwihapsari* dan Darminto \\ Jurusan Fisika, FMIPA-Institut Teknologi Sepuluh Nopember (ITS) \\ Kampus ITS Sukolilo, Surabaya 60111
}

Yudi Cahyono, Yahya Ari Pramono, dan Abdul Hafid Bajamal

Departemen Bedah Syaraf, Fakultas Kedokteran -Universitas Airlangga Kampus A, Jl. Karangmenjangan 12, Surabaya 60286

\begin{abstract}
Intisari
Telah dilakukan studi pendahuluan mengenai perancangan dan pembuatan alat penetrometer untuk menentukan konsistensi tumor otak. Selama ini konsistensi tumor otak sebagai salah satu parameter penting dalam diagnosis dan operasi tumor otak, diprediksi dengan salah satu parameter dari magnetic resonance imaging (MRI), yaitu nilai apparent diffusion coefficient (ADC). Beberapa penelitian mencoba mencari hubungan antara nilai ADC dan konsistensi tumor otak namun hasilnya sangat bervariasi. Dalam industri lainnya seperti produk pangan dan perminyakan, konsistensi suatu produk biasanya diukur dengan penetrometer. Penelitian sebelumnya mengenai pengukuran konsistensi tumor otak menggunakan penetrometer menunjukkan hubungan linier antara rasio nilai ADC tumor dibandingkan jaringan otak normal dengan nilai konsistensi tumor otak hasil pengukuran penetrometer. Namun demikian, penetrometer yang digunakan sangat berat dan besar sehingga sulit digunakan pada saat operasi bedah tumor otak. Tujuan dari studi pendahuluan ini adalah (1) menghasilkan produk penetrometer yang dapat digunakan untuk menentukan konsistensi sampel, serta (2) mencari korelasi antara nilai ADC dengan nilai konsistensi sampel hasil pengukuran penetrometer yang telah dibuat pada penelitian ini. Setelah penetrometer dibuat, pengujian pada penetrometer dilaksanakan menggunakan sampel berupa jaringan tubuh sapi. Dari hasil pengujian, didapatkan nilai penunjukan penetrometer yang lebih besar dan nilai ADC yang lebih tinggi untuk sampel dengan kekenyalan yang lebih besar.
\end{abstract}

KATA KUNCI: penetrometer; konsistensi; konsistensi tumor otak; apparent diffusion coefficient (ADC

\section{PENDAHULUAN}

Tumor otak merupakan salah satu penyakit dengan resiko tinggi karena otak merupakan salah satu organ tubuh yang sangat penting. Gangguan pada otak dapat mempengaruhi organ atau bagian tubuh lainnya. Tumor otak dibedakan atas tumor otak jinak dan tumor otak ganas. Tumor otak jinak pertumbuhannya lambat sehingga otak masih dapat menyesuaikan diri, sedangkan tumor otak ganas pertumbuhannya cepat dan mempengaruhi jaringan sekitarnya. Tumor otak berdasarkan penyebabnya dibedakan menjadi tumor otak primer yang berasal dari otak dan tumor otak metastase.

Beberapa kasus tumor otak yang banyak dijumpai di Indonesia diantaranya meduloblastoma, meningioma, dan astrositoma. Meduloblastoma biasanya terjadi pada anak-anak, sedangkan meningioma merupakan tumor jinak yang berasal dari selaput pembungkus otak. Astrositoma merupakan tumor otak yang terjadi karena mutasi pada gen-gen yang mengatur pertumbuhan sel dan berakibat pada perkembangan sel astrosit yang berlebihan dan menyebabkan tumor.

Diagnosis tumor otak awalnya ditegakkan berdasarkan keluhan dan gejala yang didapatkan dari hasil pemeriksaan

*E-MAIL: yanuritadh@physics.its.ac.id fisik serta neurologis. Penggunaan alat instrumentasi diagnostik seperti rontgen, Computed Tomography (CT) scan dan magnetic resonance imaging (MRI) memungkinkan diagnosa lanjut yang lebih tepat dan akurat.

Pengobatan atau terapi tumor otak didasarkan pada besar, lokasi dan jenisnya. Modalitas terapi yang dapat dilakukan berupa pembedahan, radioterapi, kemoterapi atau imunoterapi [1]. Pada beberapa kasus tumor otak jinak yang dilakukan pembedahan, kadang diperlukan terapi penyinaran untuk menghancurkan sel-sel tumor yang tersisa jika didapatkan sisa tumor yang tidak mungkin dieksisi. Tumor otak ganas diobati dengan pembedahan dan terapi penyinaran atau kemoterapi atau kombinasi ketiganya.

Rontgen pada tulang tengkorak dan otak biasanya hanya memberikan sedikit gambaran mengenai tumor otak. Tumor otak dapat dilihat lebih jelas baik ukuran maupun letaknya dengan menggunakan CT scan dan MRI. Biopsi yang berupa pengambilan sejumlah kecil jaringan dari tumor biasanya dilakukan untuk menentukan jenis tumor dan sifatnya (jinak atau ganas). CT scan dapat memberikan gambaran yang lebih lengkap dan jelas dalam diagnosis tumor otak, tetapi CT scan masih mempunyai beberapa kelemahan diantaranya pengenalan dan pencitraan jaringan lunak yang kurang detail dan rekonstruksi ulang gambar yang masih sulit. MRI mampu memberikan gambaran jaringan yang lebih rinci dan memberikan informasi yang lebih akurat mengenai tumor otak den- 
gan adanya aplikasi yang terdapat dalam MRI seperti diffusion weighted imaging (DWI) dan tensor perfusion imaging (TPI).

Konsistensi atau tingkat kekenyalan tumor merupakan salah satu parameter penting dalam diagnosis tumor otak. Pengetahuan tentang konsistensi tumor sangat membantu persiapan operasi dalam pemilihan cara dan teknik operasi. Ketepatan pemilihan alat akan mempercepat waktu pelaksanaan operasi dan mencegah kegagalan operasi. Konsistensi tumor otak dipengaruhi oleh kadar air di dalam jaringan, kepadatan sel serta jumlah jaringan ikat di dalamnya. Peningkatan jumlah jaringan ikat, hiperseluler pada gambaran histologi serta kadar air pada tumor yang lebih padat akan menurunkan nilai konsistensinya.

Berdasarkan konsistensinya, tumor otak dibedakan menjadi tumor lunak dan tumor kenyal. Untuk tumor dengan konsistensi kenyal, teknik pembedahan dengan ultrasound aspiration umumnya digunakan karena tidak merusak jaringan sekitar dan area penting fungsional [2]. Tumor dengan konsistensi lunak umumnya ditangani dengan teknik pembedahan laser yang mampu mengenali batas antara tumor dan otak normal [3]. Pada tumor yang sangat kenyal, digunakan beberapa teknik seperti pisau scalpel dan pinset tumor [4].

Konsistensi tumor otak selama ini dinyatakan dengan beberapa parameter dalam MRI. Beberapa studi menunjukkan hubungan konsistensi tumor otak dengan beberapa parameter dalam MRI yaitu nilai T2 pada pencitraan kerapatan proton (proton density imaging) [5], nilai fractional anisotropy [6] serta nilai apparent diffusion coefficient [7].

Akan tetapi, parameter yang banyak digunakan dalam mencari hubungan dengan konsistensi tumor otak adalah apparent diffusion coefficient (ADC) yang dapat membedakan tumor dengan jaringan otak normal, mengidentifikasi serta membuat gradasi tumor otak primer [8]. Beberapa penelitian mencoba mencari hubungan antara nilai ADC dan konsistensi tumor otak namun hasilnya sangat bervariasi $[7,8]$. Dalam industri lainnya seperti produk pangan dan perminyakan, konsistensi suatu produk biasanya diukur dengan penetrometer.

Penelitian sebelumnya mengenai pengukuran konsistensi tumor otak menggunakan penetrometer menunjukkan hubungan linier antara rasio nilai ADC tumor dibandingkan jaringan otak normal dengan nilai konsistensi tumor otak hasil pengukuran penetrometer [9]. Namun demikian, penetrometer yang digunakan sangat berat dan besar sehingga sulit digunakan pada saat operasi bedah tumor otak.

Untuk itu, dilakukan studi pendahuluan yang bertujuan untuk (1) menghasilkan produk penetrometer yang dapat digunakan untuk menentukan konsistensi sampel, serta (2) mencari korelasi antara nilai ADC dengan nilai konsistensi sampel hasil pengukuran penetrometer dari penelitian ini.

\section{DASAR TEORI}

\section{A. Penetrometer}

Penetrometer umumnya digunakan untuk menentukan nilai kekerasan atau kekenyalan suatu bahan. Penetrometer digunakan pada sejumlah industri yang berbeda untuk mengukur konsistensi dari sejumlah produk yang berbeda. Penetrometer awalnya digunakan sebagai pengukur tingkat kesolidan tanah dan biasanya digunakan pada industri perminyakan ataupun bidang-bidang lain yang berhubungan dengan pertanahan [10, 11]. Pada perkembangannya, penetrometer dapat pula digunakan dalam industri pangan untuk mengukur konsistensi berbagai macam produk pangan seperti daging hewan ternak, lemak, mentega, jelly, puding hingga yogurt [12]. Penetrometer juga digunakan untuk menentukan konsistensi pada industri pelumas dan kosmetik.

Dalam tes konsistensi menggunakan penetrometer, setiap standar tes internasional dikembangkan dengan penekan spesifik dimana setiap penekan memiliki bentuk dan berat yang berbeda bergantung pada spesifikasi produk yang akan diukur. Dalam bidang peternakan, penetrometer jarum taper (tapered penetrometer) digunakan untuk menentukan konsistensi daging hewan ataupun bahan olahan daging dengan prosedur tes ASTM D1321.

Penentuan konsistensi suatu bahan didapatkan dengan menekan sampel pada penetrometer dengan penekan standar seperti kerucut, batang atau jarum yang ditenggelamkan ke dalam bahan sampel. Hasil pengukurannya menunjukkan tingkat kekerasan atau kelunakan bahan serta tergantung pada kondisi sampel seperti ukuran, berat penekan, geometri dan waktu. Penekan penetrometer akan tenggelam ke dalam sampel semakin dalam jika sampel semakin lunak, dan angka yang ditunjukkan penetrometer juga akan semakin besar.

Prinsip operasional penetrometer bergantung pada tekanan gravitasi. Bila sebuah penetrometer dengan massa $m$ dan penekan dengan massa m' menekan suatu sampel hingga penetrometer bergeser sejauh $\mathrm{h}$, energi kinetik $\mathrm{W}$ yang dihasilkannya adalah sebesar

$$
W=m g h
$$

Resistansi terhadap tekanan yang dihasilkan oleh penetrometer pada sampel dinyatakan dengan Dutch formula [13] dan dirumuskan sebagai

$$
R=\frac{m g h}{A \Delta z} \frac{m}{m+m^{\prime}}
$$

dengan $\mathrm{R}$ adalah resistansi terhadap tekanan penetrometer $\left(\mathrm{N} / \mathrm{m}^{2}\right)$, A adalah luas/area penekan $\left(\mathrm{m}^{2}\right)$, g adalah percepatan gravitasi $\left(=9,8 \mathrm{~m} / \mathrm{s}^{2}\right), \mathrm{m}$ adalah massa penetrometer $(\mathrm{kg}), \mathrm{m}$ ' adalah massa penekan $(\mathrm{kg})$, h adalah pergeseran penetrometer (m), dan $\Delta \mathrm{z}$ adalah kedalaman tekanan atau pergeseran yang terjadi pada sampel $(\mathrm{m})$.

Bila digunakan penetrometer dengan massa $m$ yang sama dan penekan dengan luas A dan massa m' yang sama serta diterapkan pergeseran $\mathrm{h}$ yang sama untuk setiap sampel, akan didapatkan $\Delta \mathrm{z}$ yang berbeda untuk setiap sampel yang mempunyai konsistensi yang berbeda. Hal ini disebabkan perbedaan resistansi terhadap tekanan $\mathrm{R}$ pada sampel dengan konsistensi berbeda. Semakin lunak suatu sampel, konsistensinya akan semakin tinggi, resistansinya terhadap tekanan akan semakin kecil dan sebaliknya, pergeseran $\Delta \mathrm{z}$ yang dihasilkan akan semakin besar.

Penetrometer digital berbasis mikrokontroler memiliki beberapa kelebihan dibandingkan penetrometer manual yaitu 
dapat dioperasikan dan ditampilkan secara otomatis dan operator dapat memilih jangka waktu yang diinginkan untuk menjatuhkan penekan. Hasil pengukuran yang didapat juga lebih akurat karena dioperasikan secara otomatis sehingga pengaruh kesalahan pengukuran dari operator dapat diperkecil. Pada penetrometer digital, penekan diletakkan pada permukaan sampel dan percobaan dimulai dengan menekan tombol sehingga penekan mulai tenggelam ke dalam sampel di bawah pengaruh gravitasi. Hasil pengukuran penetrometer menunjukkan jarak yang dihantarkan melalui penekan di dalam sampel di bawah pengaruh gravitasi untuk jangka waktu tertentu yang tetap.

Sejauh ini belum ditemukan peralatan penetrometer yang dapat digunakan untuk pengukuran konsistensi otak manusia dalam skala industri [14]. Penelitian sebelumnya menemukan hubungan linier antara rasio nilai ADC tumor dibandingkan jaringan otak normal dengan nilai konsistensi tumor otak hasil pengukuran penetrometer [9]. Penelitian tersebut menggunakan penetrometer digital Precision katalog 73515 (Petroleum Analyzer Company, Pasadena, USA) milik Fakultas Kedokteran Hewan, Universitas Airlangga, Surabaya. Nilai konsistensi didapatkan dengan menggunakan standar tes ASTM D5. Penetrometer yang digunakan berukuran besar dan berat sehingga sulit untuk digunakan di dalam ruangan operasi bedah. Dari penelitian tersebut, diperlukan penetrometer yang berukuran lebih kecil dan dapat digunakan untuk menentukan konsistensi tumor otak secara in vitro di dalam ruang operasi.

\section{B. Apparent Diffusion Coefficient (ADC) pada MRI}

Dalam MRI, nilai ADC didapatkan dengan salah satu metode pada MRI difusi yaitu diffusion weighted imaging (DWI). MRI difusi digunakan untuk mengamati aliran fluida di dalam tubuh dengan memanfaatkan sifat difusi proton dalam molekul-molekul air di dalam tubuh manusia. MRI difusi bekerja berdasarkan hukum difusi Fick dimana besarnya difusi pada suatu fluida akan sebanding dengan perubahan konsentrasi tiap satuan jarak (lihat persamaan 3).

$$
J=-D \frac{\partial C}{\partial x}
$$

J menyatakan difusi yang terjadi pada suatu penampang, D adalah koefisien difusi, C adalah konsentrasi dan x menyatakan jarak. Difusi pada fluida ini disebabkan adanya gerak acak Brown dari molekul dalam fluida yang terus-menerus bergerak dan bertabrakan dengan sekelilingnya.

Pada MRI, sinyal didapatkan dengan cara membangkitkan medan magnet homogen pada atom agar spin-spin pada atom terpolarisasi. Penggambaran spasial dalam 3 dimensi dimungkinkan oleh adanya sistem gradien yang terdiri dari tiga lilitan saling tegak lurus (dalam arah sumbu $\mathrm{x}, \mathrm{y}$, dan z) yang berfungsi untuk membangkitkan medan berubah waktu (medan magnet gradien) agar keragaman spasialnya dapat diatur. Gelombang radio lalu digetarkan sehingga resonansinya dapat ditangkap oleh suatu sensor.
Pada DWI, sinyal terbentuk dengan menggunakan dua buah medan magnet gradien difusi mengikuti sekuens (urutan) Stejskal-Tanner [15]. Gradien difusi yang pertama dibangkitkan pada satu arah, dan setelah waktu tertentu, gradien difusi kedua dibangkitkan pada arah yang berlawanan. Dari proses ini, sinyal difusi terbentuk dengan intensitas sebesar

$$
S=S_{\circ} e^{-b D}
$$

dengan $\mathrm{S}$ adalah sinyal difusi yang dihasilkan, $\mathrm{S}_{\circ}$ adalah sinyal tanpa gradien difusi, $\mathrm{b}$ adalah faktor difusi atau faktor $\mathrm{b}$ dan D adalah koefisien difusi. Untuk sekuens Stejskal-Tanner, faktor difusi yang digunakan adalah sebesar

$$
b=\gamma^{2} G^{2} \delta^{2} \delta(\Delta-\delta / 3)
$$

dengan $\gamma$ adalah giromagnetik rasio dari proton $(=42$ $\mathrm{MHz} / \mathrm{T}), \mathrm{G}$ adalah besarnya gradien difusi, $\delta$ adalah durasi gradien difusi, dan $\Delta$ adalah waktu antara gradien difusi.

Untuk mendapatkan nilai ADC, peta ADC atau peta difusi dibuat dengan cara menggabungkan dua citra DWI yang mempunyai paramater pemindaian yang sama, namun dengan faktor difusi yang berbeda. Berdasarkan persamaan 4, untuk sinyal dengan faktor difusi yang berbeda (misal S dengan $\mathrm{b}>$ 0 dan $S_{\circ}$ dengan $b=0$ ), dapat dibuat grafik logaritmik natural antara $\mathrm{S} / \mathrm{S}$ 。 dengan $\mathrm{b}$ untuk menentukan koefisien difusi $\mathrm{D}$ atau seringkali disebut sebagai nilai ADC.

\section{METODOLOGI}

\section{A. Perancangan dan Pembuatan Penetrometer Tumor Otak}

Penetrometer digital dibuat menggunakan sensor strain gauge dan skema peralatan penetrometer dapat dilihat pada Gambar 1. Pada penetrometer terdapat sistem elektronik dan sistem mekanik. Sistem elektronik pada penetrometer meliputi catu daya, bagian pewaktu yang dikendalikan oleh mikrokontroler, sensor strain gauge, penguat pengkondisi sinyal, serta tampilan digital. Sistem mekanik terdiri dari motor DC yang dikendalikan oleh mikrokontroler serta sistem mekanik pengangkat jarum penekan.

Sensor strain gauge berfungsi mengubah besaran pergeseran menjadi data tegangan, yang akan dikuatkan dan diolah dalam penguat pengkondisi sinyal. Di dalam sistem ini juga terdapat sistem analog to digital converter (ADC) yang mengubah data dari pengondisi sinyal dalam bentuk analog menjadi bentuk digital. Selanjutnya, mikrokontroler AVR ATMega8 akan memproses data digital sehingga hasil pengukuran dapat ditampilkan pada layar tampilan LCD.

Pada saat pengoperasian penetrometer, penekan diatur agar jatuh sesuai waktu standar yang telah ditentukan sebelumnya dan dikendalikan oleh mikrokontroler. Pada saat penekan masuk ke dalam sampel akibat tekanan gravitasi, skala yang ada pada layar tampilan akan menunjukkan nilai konsistensi sampel tersebut dalam skala mm. 


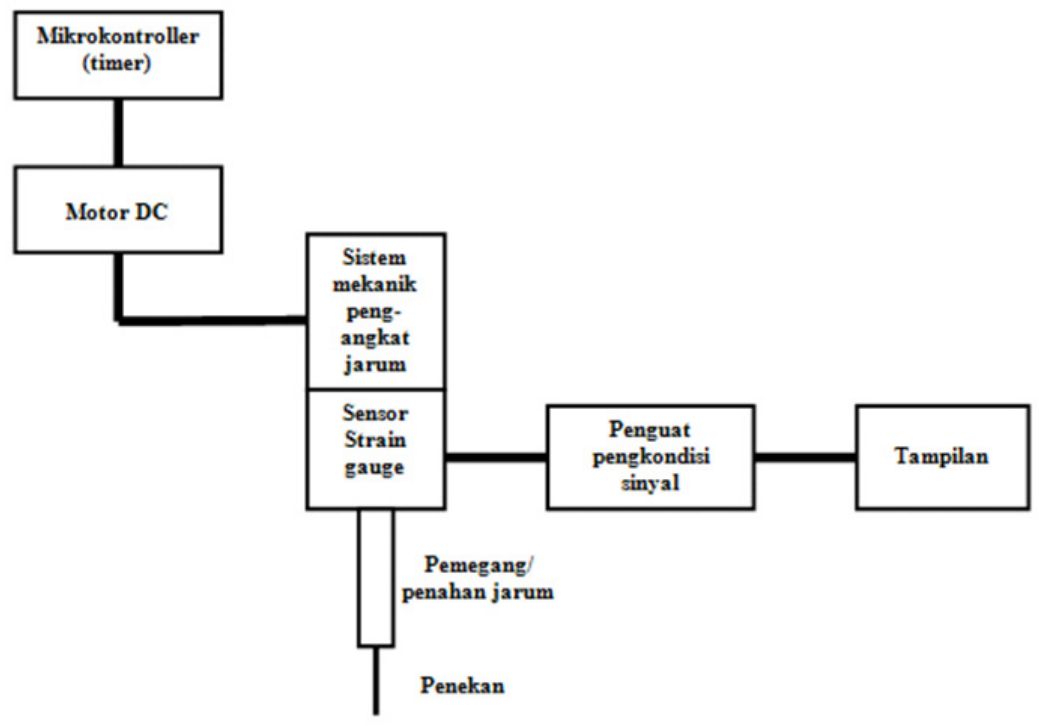

Gambar 1: Desain alat penetrometer

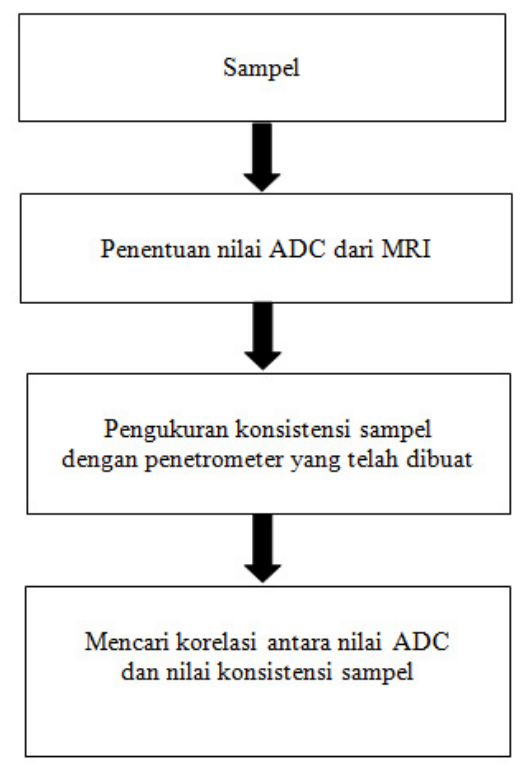

Gambar 2: Diagram alir pengambilan data pada pengujian

\section{B. Pengujian Alat dan Pengambilan Data}

Alat penetrometer yang telah dibuat diuji menggunakan sampel berupa jaringan tubuh sapi berdimensi $2,5 \mathrm{~cm} \times 2,5$ $\mathrm{cm} \times 2,5 \mathrm{~cm}$ yang terdiri dari jaringan lemak, otak, hati, daging, tendon, dan tulang lunak. Pada studi pendahuluan ini, sampel berupa tumor otak tidak diujikan. Diagram alir metode pengambilan data dalam pengujian ini digambarkan pada Gambar 2.

Sebelum konsistensi sampel diukur menggunakan penetrometer yang telah dibuat, nilai ADC dari sampel telah ditentukan dengan MRI pada pengujian ini. Pengambilan data nilai ADC pada jaringan tubuh sapi dengan pemeriksaan MRI dilakukan secara terpisah di Departemen Radiologi, Fakultas Kedokteran Universitas Airlangga Surabaya. Nilai ADC didapatkan dari MRI dengan metode Diffusion-Weighted Imaging (DWI) dengan menggambarkan peta difusi antara S/S0 dengan b seperti dijelaskan pada bagian sebelumnya.

Setelah itu, konsistensi dari sampel diukur menggunakan penetrometer yang telah dibuat. Pengambilan data dilakukan dengan cara meletakkan sampel ke dalam cawan pengukur berdiameter $3 \mathrm{~cm}$ pada meja ukur dan menekan sampel selama 60 detik. Setelah data nilai ADC dan konsistensi didapatkan, korelasi antara nilai ADC dan nilai konsistensi sampel hasil pengukuran penetrometer yang telah dibuat dapat ditentukan.

\section{HASIL DAN PEMBAHASAN}

Tabel 1 menunjukkan data nilai konsistensi hasil pengukuran penetrometer. Dari hasil tersebut, didapatkan nilai konsistensi yang semakin tinggi untuk sampel dengan kekenyalan yang semakin tinggi. Hal ini sejalan dengan hipotesis awal yang merumuskan bahwa jika sampel semakin lunak, angka yang ditunjukkan penetrometer juga akan semakin besar. Tabel 2 menunjukkan data nilai konsistensi serta nilai ADC sampel. Tabel tersebut menunjukkan nilai ADC yang semakin tinggi untuk sampel dengan nilai konsistensi yang semakin besar.

Dari hasil pengujian tersebut, dapat diketahui bahwa penetrometer digital yang telah dibuat dapat digunakan untuk menentukan konsistensi suatu bahan. Penetrometer ini mempunyai prinsip kerja yang sama dengan dengan penetrometer yang digunakan untuk menentukan konsistensi tumor otak pada penelitian sebelumnya, yaitu menggunakan prinsip tekanan gravitasi. Akan tetapi, penetrometer hasil studi ini dapat menampilkan hasil pengukuran pada tampilan digital 
TABEL I: Data nilai konsistensi hasil pengujian penetrometer

\begin{tabular}{lccccc}
\hline \hline Jaringan & \multicolumn{6}{c}{ P engukuran } & Konsistensi Rentangan \\
tubuh sapi & 1 & 2 & 3 & rata-rata & \\
\hline Lemak & 12 & 14 & 10 & 12,00 & $10-14$ \\
Otak & 12 & 10 & 12 & 11,33 & $10-12$ \\
Hati & 9 & 9 & 13 & 10,33 & $9-13$ \\
Daging & 8 & 9 & 11 & 9,33 & $8-11$ \\
Tendon & 6 & 7 & 9 & 7,33 & $6-9$ \\
Tulang Rawan & 4 & 3 & 3 & 3,33 & $3-4$ \\
\hline \hline
\end{tabular}

TABEL II: Data nilai konsistensi dan ADC sampel

\begin{tabular}{lcc}
\hline $\begin{array}{l}\text { Jaringan } \\
\text { tubuh sapi }\end{array}$ & $\begin{array}{c}\text { Rentang Nilai } \\
\text { Konsistensi }\end{array}$ & $\begin{array}{c}\text { Rentangan } \\
\text { Nilai ADC }\end{array}$ \\
\hline Lemak & $10-14$ & $1,230-1,300$ \\
Otak & $10-12$ & $0,978-1,048$ \\
Hati & $9-13$ & $0,726-0,796$ \\
Daging & $8-11$ & $0,586-0,614$ \\
Tendon & $6-9$ & $0,320-0,362$ \\
Tulang Rawan & $3-4$ & $0,222-0,236$ \\
\hline \hline
\end{tabular}

sehingga hasil pengukuran lebih mudah dibaca. Penetrometer pada penelitian sebelumnya menggunakan jarum penunjuk untuk menunjukkan hasil pengukuran.

Pada penetrometer ini, penekan sampel dapat digerakkan secara otomatis dan waktu penekanannya dapat diatur secara otomatis sehingga mengurangi kesalahan pada saat pen- goperasian alat. Pada penetrometer sebelumnya, pengaturan waktu untuk menekan sampel dilakukan secara manual oleh operator. Selain itu, penetrometer ini berukuran lebih kecil dibandingkan sebelumnya, sehingga dapat digunakan di dalam ruang operasi untuk menentukan konsistensi tumor otak secara in vitro. Pengambilan data pada sampel juga dapat dilakukan secara langsung tanpa harus membawa sampel ke tempat yang berbeda, yang dapat menimbulkan kesalahan pada saat pengukuran sampel.

\section{SIMPULAN}

Telah dilakukan studi pendahuluan mengenai perancangan dan pembuatan alat penetrometer untuk menentukan konsistensi tumor otak. Setelah penetrometer dibuat, dilakukan pengujian dengan sampel berupa jaringan tubuh sapi. Dalam studi pendahuluan ini, sampel berupa tumor otak tidak digunakan. Dari pengujian tersebut, didapatkan nilai konsistensi yang tinggi untuk sampel dengan kekenyalan yang tinggi. Selain itu diketahui bahwa semakin tinggi nilai konsistensi sampel, semakin tinggi nilai ADC yang ditunjukkan. Penelitian ini dapat dilanjutkan dengan pengembangan lebih lanjut pada perancangan dan pembuatan alat dengan membuat penetrometer yang berukuran lebih kecil, sehingga dapat digunakan di dalam ruang operasi untuk menentukan konsistensi tumor otak secara in vitro.
[1] Riadi, D., Terapi Pembedahan Tumor Otak, Cermin Dunia Kedokteran 77: 30 - 32 (1992).

[2] Fasano VA, Zeme S, Frego L.,J Neurosurg. Sci., 25(1), 35-40 (1981).

[3] Omori S, Nakumura R, Muragaki Y, Mid-Infrared Robotic Laser Surgery System in Neurosurgery, 47-55 (2007).

[4] Turgut M, Ozcan OE, Benli K, Aust. NZ Surg., 66(3), 144-150 (1996).

[5] Yamaguchi N, Kawase T, Sagih M, Surg. Neurol., 48, 579-583 (1997).

[6] Kashimura H, Inoue T, Ogaswara K, J Neurosurg., 107(4), 784 787 (2007).

[7] Pierallini A, Radiology, 239 (1), 223 - 231 (2006).

[8] Mauricio C, Smith JK, Kwock L, Am J Neuroradiol, 22, 60-64 (2001).

[9] Pramono, YA., Hubungan Nilai Aparent Diffusion Coefficient (ADC) pada Diffusion-Weighted MRI (DW MRI) dengan Nilai Konsistensi Tumor Otak, Karya Akhir, Dep. Bedah Syaraf,
Fakultas Kedokteran, Universitas Airlangga Surabaya, 2008

[10] Begemann, HKS., The Friction Jacket Cone as an Aid in Determining the Soil Profile, Proceedings of 6th ICSMFE, Montreal, Quebec, Canada, 1: 17-20 (1965).

[11] De Reister, J., Journal of SMFE Division, ASCE, 97, SM-2, 457-472 (1971)

[12] Hayakawa M and Deman JM., Journal of Texture Studies, 13(2), 201-210 (1982).

[13] Sanglerat G, The Penetrometer and Soil Exploration. Developments in Geotechnical Engineering 1(Elsevier Publishing, New York,1972)

[14] Goldenberg WS and Shah R, A Useful Tool for the Determination of Consistency in Semi-Solid Substances, www. koehlerinstrument.com/ literature/ applications/ Penetration- Paper, 2007.

[15] Stejskal, EO dan Tabber, JE.,The Journal of Chemical Physics, 42(1), 288 - 293(1965). 